\title{
Lysophosphatidic acid upregulates connective tissue growth factor expression in osteoblasts through the GPCR/PKC and PKA pathways
}

\author{
ZI-LI YU ${ }^{1}$, DIAN-QI LI ${ }^{1}$, XIANG-YU HUANG ${ }^{1}, \mathrm{XIN} \mathrm{XING}^{1}$, RU-QING YU ${ }^{1}, \mathrm{ZHI} \mathrm{LI}^{1,2}$ and ZU-BING LI ${ }^{1,2}$ \\ ${ }^{1}$ The State Key Laboratory Breeding Base of Basic Science of Stomatology (Hubei-MOST) and Key Laboratory \\ of Oral Biomedicine Ministry of Education, School and Hospital of Stomatology, Wuhan University; \\ ${ }^{2}$ Department of Oral and Maxillofacial Surgery, School and Hospital of Stomatology, \\ Wuhan University, Wuhan, Hubei 430079, P.R. China
}

Received May 1, 2015; Accepted December 29, 2015

DOI: $10.3892 / \mathrm{ijmm} .2016 .2450$

\begin{abstract}
Lysophosphatidic acid (LPA) is an efficient, bioactive phospholipid involved in various biological processes. In this study, LPA-induced connective tissue growth factor (CTGF/ CCN2) expression and the underlying mechanisms were investigated using the MC3T3-E1 cell line. The MC3T3-E1 cells were stimulated with an inhibitor of LPA receptors, an activator and inhibitor of protein kinase $\mathrm{C}(\mathrm{PKC})$ and protein kinase A (PKA) for indicated periods of time. RT-qPCR and western blot analyses were used to measure the expression levels of CCN2. Immunofluorescence staining was used to observe the translocation of PKC. The mRNA expression level of CCN2 was increased following stimulation of the cells with LPA; LPA transiently induced the mRNA expression of CCN2; maximum expression levels were observed $2 \mathrm{~h}$ following stimulation with LPA. This increase was accompanied by $\mathrm{CCN} 2$ protein synthesis. LPA receptor ${ }_{1 / 3}$ was inhibited by Ki16425, a specific inhibitor of $\mathrm{LPA}_{1 / 3}$; as a result, the LPA-induced increase in CCN2 expression was abrogated. LPA also induced the membrane translocation of PKC and enhanced PKC activity in the osteoblasts. Pre-treatment of the osteoblasts with staurosporine prevented the increase in $\mathrm{CCN} 2$ expression by induced
\end{abstract}

Correspondence to: Professor Zu-Bing Li, Department of Oral and Maxillofacial Surgery, School and Hospital of Stomatology, Wuhan University, 237 Luoyu Road, Wuhan, Hubei 430079, P.R. China E-mail: lizubing0827@163.com

Abbreviations: LPA, lysophosphatidic acid; CTGF, connective tissue growth factor; GPCRs, G-protein-coupled receptors; PKC, protein kinase C; PKA, protein kinase A; PMA, phorbol 12-myristate 13-acetate; $\alpha$-MEM, $\alpha$-modified minimal essential medium; FBS, fetal bovine serum; DMSO, dimethyl sulfoxide; RT-qPCR, reverse transcriptionquantitative polymerase chain reaction; GAPDH, glyceraldehyde3-phosphate dehydrogenase; PBS, phosphate-buffered saline; PFA, paraformaldehyde; cAMP, cyclic AMP

Key words: lysophosphatidic acid, connective tissue growth factor/ $\mathrm{CCN} 2$, protein kinase $\mathrm{C}$, protein kinase $\mathrm{A}$, signaling pathway by LPA, and the activation of PKC by phorbol 12-myristate 13-acetate (PMA) enhanced CCN2 expression, indicating that the PKC pathway is involved in the LPA-induced increase in CCN2 expression. The interference of PKA signaling also led to the induction of CCN2 expresion by LPA. These data indicate that LPA increases CCN2 expression through the activation of PKC and PKA. Thus, the regulatory functions of the PKC and PKA pathways are implicated in the LPA-induced increase in CCN2 expression.

\section{Introduction}

Lysophosphatidic acid (LPA) is an efficient, bioactive phospholipid involved in various biological processes, including cell proliferation, differentiation, apoptosis, adhesion, chemotaxis, survival and cancer cell invasion (1-6).

LPA is present in mammalian serum at concentrations of 1-5 $\mu \mathrm{M}$; newly-formed LPA is rapidly released into the extracellular environment when platelets are activated (7). It has also been demonstrated that LPA is produced when $\mathrm{P} 2 \mathrm{X} 7$ receptors expressed in osteoblasts are activated (8). Furthermore, LPA is released by osteoblasts (8), which suggests that LPA may be implicated in fracture healing.

LPA is a important signaling molecule exhibiting bioactive functions through receptors on the cytomembrane. At least 5 G-protein-coupled receptors (GPCRs) have been identified as LPA-specific receptors: $\mathrm{LPA}_{1}, \mathrm{LPA}_{2}, \mathrm{LPA}_{3}, \mathrm{LPA}_{4}$ and $\mathrm{LPA}_{5}(9,10)$. These receptors are expressed in different cell types, including osteoblasts, epithelial cells and skeletal muscle cells (2,11-13).

Connective tissue growth factor (CTGF/CCN2) is a member of the CCN (Cyr61/CCN1, CTGF/CCN2 and NOV/CCN3) family, which also includes CCN4/WISP1, CCN5/WIPS2 and CCN6/WISP3 $(14,15)$. CCN2 promotes the proliferation and differentiation of osteoblasts; CCN2 is also involved in bone development and fracture healing (16-18).

LPA directly induces the production of CCN2 in epithelial cells, myoblasts and human renal fibroblasts $(13,19,20)$ by binding to LPA receptors expressed in these cells. LPA receptors are also expressed in osteoblasts $(2,3,11)$. However, whether LPA is capable of inducing changes in the levels of 
CCN2 in osteoblasts remains unclear. Thus, in the present study, we aimed to investigate the possible regulatory effects of LPA on CCN2 expression in osteoblasts.

In the present study, we also aimed to elucidate the mechanisms through which LPA influences CCN2 expression in osteoblasts. Our results suggest that LPA affects CCN2 expression in osteoblasts through the GPCR/protein kinase C (PKC) and protein kinase $\mathrm{A}$ (PKA) pathways.

\section{Materials and methods}

Reagents. 1-Oleoyl lysophosphatidic acid (sodium salt) (LPA; item no. 62215; Cayman Chemical Co., Ann Arbor, MI, USA) and Kil16425 (S1315; Selleck Chemicals, Houston, TX, USA) were dissolved in $4 \mathrm{mM}$ sterile stock solutions and stored at $-20^{\circ} \mathrm{C}$ until use. Phorbol 12-myristate 13-acetate (PMA; S1819; PKA agonist), forskolin (S1612; PKA activator), staurosporine (S1882; PKC inhibitor) and H-89 (S1643; selective inhibitor of PKA) were purchased from Beyotime Institute of Biotechnology (Shanghai, China). CCN2 polyclonal rabbit antimouse CTGF primary antibody (ab6992, diluted 1:2,000) and glyceraldehyde-3-phosphate dehydrogenase (GAPDH) rabbit anti-GAPDH primary antibody (ab181602, diluted 1:10,000) were purchased from Abcam (Cambridge, UK).

Cell cultures and cell treatment. The MC3T3-E1 cell line (China Center for Type Culture Collection, Wuhan, China) was cultured in $\alpha$-modified minimal essential medium ( $\alpha$-MEM) containing $10 \%$ fetal bovine serum (FBS) (both from HyClone, Logan, UT, USA), $100 \mathrm{U} / \mathrm{ml}$ of penicillin and $100 \mu \mathrm{g} / \mathrm{ml}$ of streptomycin at $37^{\circ} \mathrm{C}$ in a $5 \% \mathrm{CO}_{2}$ atmosphere; the medium was changed to fresh medium at an interval of 3 days. The cells were seeded on 6 -well plates or $6 \mathrm{~cm}$ dishes to examine gene and protein expression. After the cells reached confluence, the culture medium was replaced with $\alpha$-MEM and $1 \%$ penicillin-streptomycin without FBS for $12 \mathrm{~h}$. The medium was then replaced with $\alpha$-MEM containing $4 \%$ bovine seum albumin (BSA) and varying doses of LPA, PMA or forskolin. Inhibitors, such as staurosporine and $\mathrm{H}-89$, were used to suppress PKC and PKA activity, respectively. After co-incubation was performed for the indicated periods of time (0-12 h), the MC3T3-E1 cells were lysed for the subsequent analysis of RNA and protein expression.

Measurement of cell viability. The viability of the MC3T3-E1 cells was determined as previously described (21). Briefly, following incubation of the cells with increasing concentrations of LPA (0-40 $\mu \mathrm{M})$ for different periods of time (12 to $72 \mathrm{~h}$ ), cell viability was determined using a cell viability analyzer (Beckman Coulter, Fullerton, CA, USA).

3-(4,5-Dimethylthiazol-2-yl)-2,5-diphenyltetrazolium bromide (MTT) assay. MTT assay was performed as described in a previous study (22). Briefly, the MC3T3-E1 cells were seeded in 96-well plates $\left(3 \times 10^{3}\right.$ cells/well) and incubated with increasing concentrations of LPA $(0-40 \mu \mathrm{M})$. At the end of the incubation period, $20 \mu \mathrm{l}$ of $5 \mathrm{mg} / \mathrm{ml}$ MTT were added; the cells were then further incubated for $4 \mathrm{~h}$. Subsequently, the supernatant was removed, and $150 \mu \mathrm{l}$ of dimethyl sulfoxide (DMSO) were added to each well. The absorbance of each well was detected at $490 \mathrm{~nm}$. Data are presented as percentage of the control group.
$R N A$ isolation and reverse transcription-quantitative polymerase chain reaction ( $R T-q P C R)$. RNA isolation and RT-qPCR were performed as previously described (23). Briefly, total RNA was isolated from the ME3T3-E1 cells in each treatment group using TRIzol reagent (Invitrogen, Carlsbad, CA, USA) according to the manufacturer's instructions. cDNA was synthesized from $1 \mu \mathrm{g}$ of total RNA using a Revert Aid First-Strand cDNA Synthesis kit (\#K1622; Thermo Fisher Scientific, Waltham, MA, USA). The obtained cDNA was then amplified by quantitative PCR (qPCR) using an ABI 7900 HT Real-Time PCR system, (Applied Biosystems, Foster City, CA, USA) and SYBR $^{\circledR}$-Green Real-Time PCR Master Mix (Toyobo, Tokyo, Japan), under the following conditions: stage $1,95^{\circ} \mathrm{C}$ for $10 \mathrm{~min}$; stage $2,95^{\circ} \mathrm{C}$ for $10 \mathrm{sec}, 55^{\circ} \mathrm{C}$ for $20 \mathrm{sec}$, followed by 40 cycles of $72^{\circ} \mathrm{C}$ for $15 \mathrm{sec}$; stage 3 , melt curve stage. GAPDH was used for the normalization of gene expression. Relative gene expression was analyzed using the $2^{-\Delta \Delta \mathrm{Ct}}$ method based on normalization to the endogenous control, GAPDH, and calculation of the threshold cycle $(\mathrm{Ct})$ value difference. The results were represented as a fold change of the comparative expression level. The sequences of the forward and reverse primers were as follows: 5'-GCCTACCGACTGGAA GACACATTT-3' and 5'-TTACGCCATGTCTCCGTACA TCTT-3' for the CCN2 gene; 5'-ACCACAGTCCATGCCA TCAC-3' and 5'-TCCACCACCCTGTTGCTGTA-3' for the internal control GAPDH gene.

Protein extraction and western blot analysis. The cells were treated with the indicated stimulants (LPA, LPA + Kil16425, LPA + staurosporine, PMA, LPA + H-89, forskolin, or $\mathrm{LPA}+$ forskolin) for $6 \mathrm{~h}$. Subsequently, the cells were then washed thrice with phosphate-buffered saline (PBS) and treated with RIPA lysis buffer. The cell lysates were cleared by centrifugation; protein concentration in the supernatant was measured by bicinchoninic acid (BCA) protein assay (Thermo Fisher Scientific). Total proteins $(20 \mu \mathrm{g})$ were separated through $10 \%$ sodium dodecyl sulfate (SDS)-polyacrylamide gel electrophoresis and the proteins were then transferred onto PVDF membranes (Bio-Rad, Hercules, CA, USA). The membranes were blocked with $5 \%(\mathrm{w} / \mathrm{v})$ nonfat milk and incubated overnight with the primary antibodies (CCN2, PKC or GAPDH) at the specified dilutions in TBST buffer (CW0043; Beijing Conwin Biotech Co., Beijing, China) according to the manufacturer's instructions. Protein expression was detected using an enhanced chemiluminescence reagent (Thermo Fisher Scientific). GADPH was used as an internal control protein.

$P K C$ activity assay. PKC activity was assessed by determining the translocation of PKC from the cytosol to the membrane. After the cells were treated with the indicated stimulants for the indicated periods of time, PKC in the cytosol and in the membrane of MC3T3-E1 cells was extracted using a Mem-PER Plus Membrane Protein Extraction kit (Thermo Fisher Scientific). PKC expression in the cytosol and membrane was then determined by western blot analysis. The membrane translocation of PKC was also investigated by immunofluorescence. Briefly, the MC3T3-E1 cells were plated on cover slips and fixed with $4 \%$ paraformaldehyde (PFA) for $30 \mathrm{~min}$ at room temperature. The cells were then washed thrice with PBS buffer, permeabilized with PBS buffer containing 0.1\% Triton X-100 and 

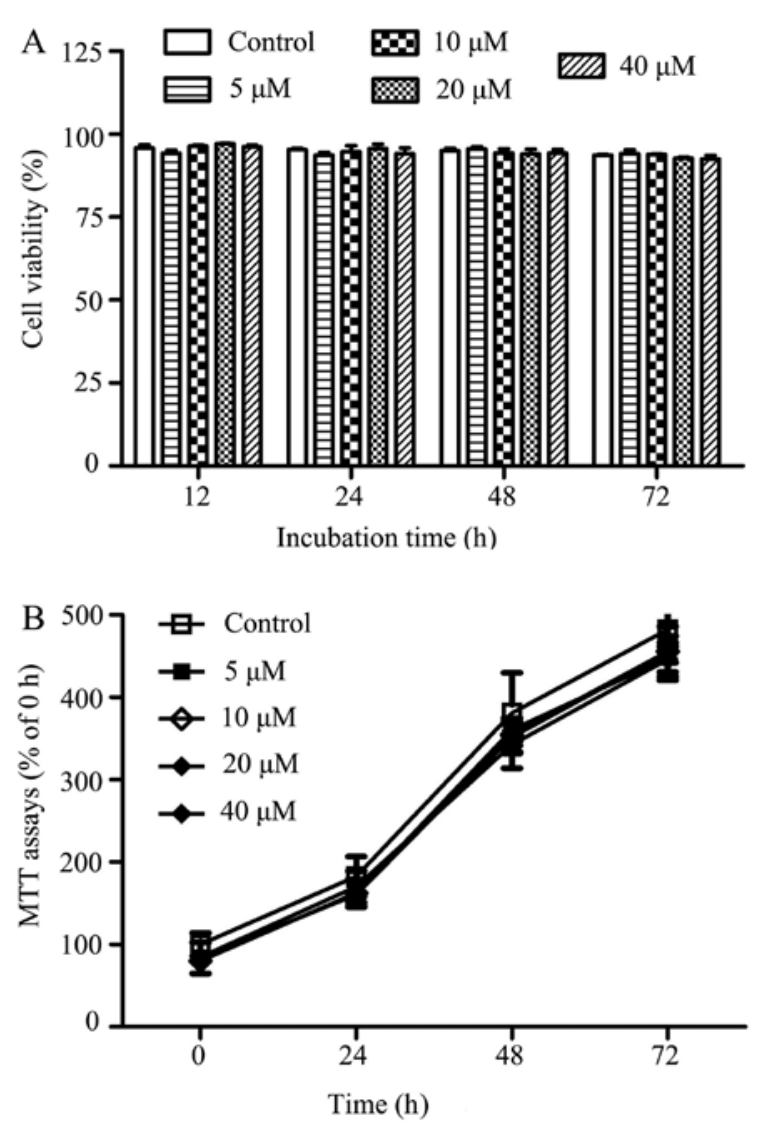

Figure 1. Effect of LPA on the viability and proliferation of MC3T3-E1 cells. Cell viability and MTT assays were performed (A) to examine the cytotoxic effects of lysophosphatidic acid (LPA) on MC3T3-E1 cells, and (B) to examine the effects of LPA on the proliferation of MC3T3-E1 cells.

blocked with $1 \%$ BSA. The cells were then incubated with PKC antibody (P5704; Sigma, St. Louis, MO, USA) for $2 \mathrm{~h}$ at $37^{\circ} \mathrm{C}$. The cells were washed again with PBS buffer thrice and incubated with PE-labeled secondary antibody (CW0113; Beijing Conwin Biotech Co.). The fluorochrome dye, 4',6-diamidino2-phenylindole (DAPI), was used to visualize the cell nuclei. Images were captured using a fluorescence microscope (Leica Microsystems GmbH, Wetzlar, Germany).

Statistical analysis. Data were analyzed by one-way analysis of variance (ANOVA) using GraphPad Prism 5.0 software. Data are expressed as the means \pm standard error of the mean (SEM) of 3 independent experiments. A value of $\mathrm{P}<0.05$ was considered to indicate a statistically significant difference.

\section{Results}

Effects of LPA on the viability and proliferation of MC3T3-EI cells. We initially examined the effects of LPA on the viability and proliferation of the MC3T3-E1 cells. The results of cell viability assay demonstrated that LPA did not exert cytotoxic effects on the MC3T3-E1 cells (Fig. 1A). A previous study reported that LPA induced an increase in DNA synthesis in rat osteoblasts in vitro (24). However, our results from MTT assay revealed that increasing concentrations of LPA did not affect MC3T3-E1 cell proliferation in vitro (Fig. 1B).
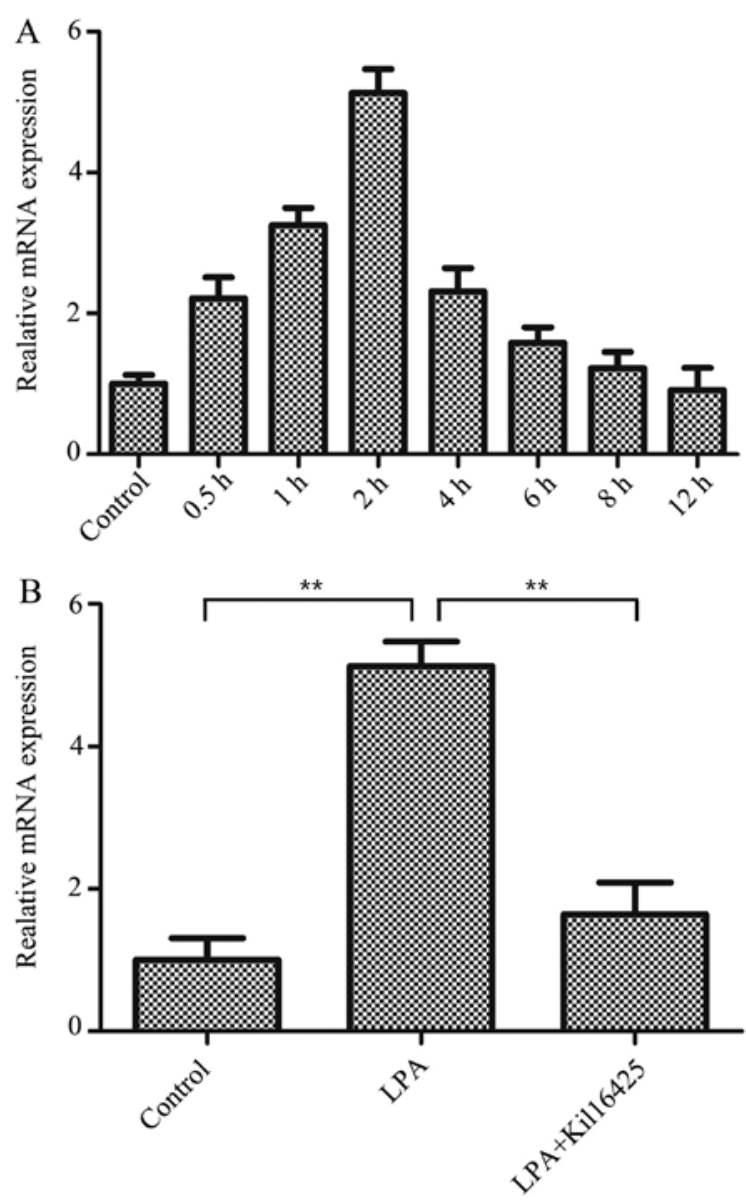

Figure 2. Pattern of CCN2 expression in lysophosphatidic acid (LPA)-stimulated MC3T3-E1 cells. (A) MC3T3-E1 cells were stimulated with $20 \mu \mathrm{M}$ LPA for the indicated periods of time. (B) MC3T3-E1 cells were treated with or without Ki16425 $\left(20 \mu \mathrm{M}\right.$; a specific inhibitor of $\left.\mathrm{LPA}_{1 / 3}\right)$ for 30 min were subsequently stimulated with LPA for $2 \mathrm{~h}$; the CCN2 mRNA expression levels were measured by RT-qPCR. ${ }^{* *} \mathrm{P}<0.01$.

CCN2 expression in LPA-stimulated MC3T3-E1 cells. The MC3T3-E1 cells were stimulated with $20 \mu \mathrm{M} \mathrm{LPA}$ and $4 \%$ BSA for $0.5,1,2,4,6,8$ and $12 \mathrm{~h}$, in order to examine the effects of LPA on CCN2 expression in osteoblasts. The CCN2 mRNA expression levels were measured by RT-qPCR. The results revealed that LPA transiently induced the mRNA expression of $\mathrm{CCN} 2$; maximum expression levels were observed $2 \mathrm{~h}$ following stimulation. The mRNA expression levels of CCN2 subsequently decreased (Fig. 2A). The results from western blot analysis revealed that the $\mathrm{CCN} 2$ protein expression levels was similarly enhanced following $6 \mathrm{~h}$ of stimulation with LPA (Fig. 3D).

Kil6425 antagonizes the LPA-induced increase in CCN2 expression in osteoblasts. LPA elicits its functions through receptors on plasma membranes; MC3T3-E1 cells express LPA-specific receptors with the following relative abundance pattern: $\mathrm{LPA}_{1}>\mathrm{LPA}_{4}>\mathrm{LPA}_{2}>\mathrm{LPA}_{3}$ (2). Thus, in this study, we wished to determine whether Kill6425, a specific inhibitor of $\mathrm{LPA}_{1 / 3}(25)$, is was capable of antagonizing the effects of LPA on CCN2 expression in MC3T3-E1 cells. We found that pre-treatment with Ki16425 $(20 \mu \mathrm{M})$ significantly reduced the LPA-induced increase in the mRNA expression of CCN2 in the MC3T3-E1 cells (Fig. 2B). Kil16425 also blocked the 

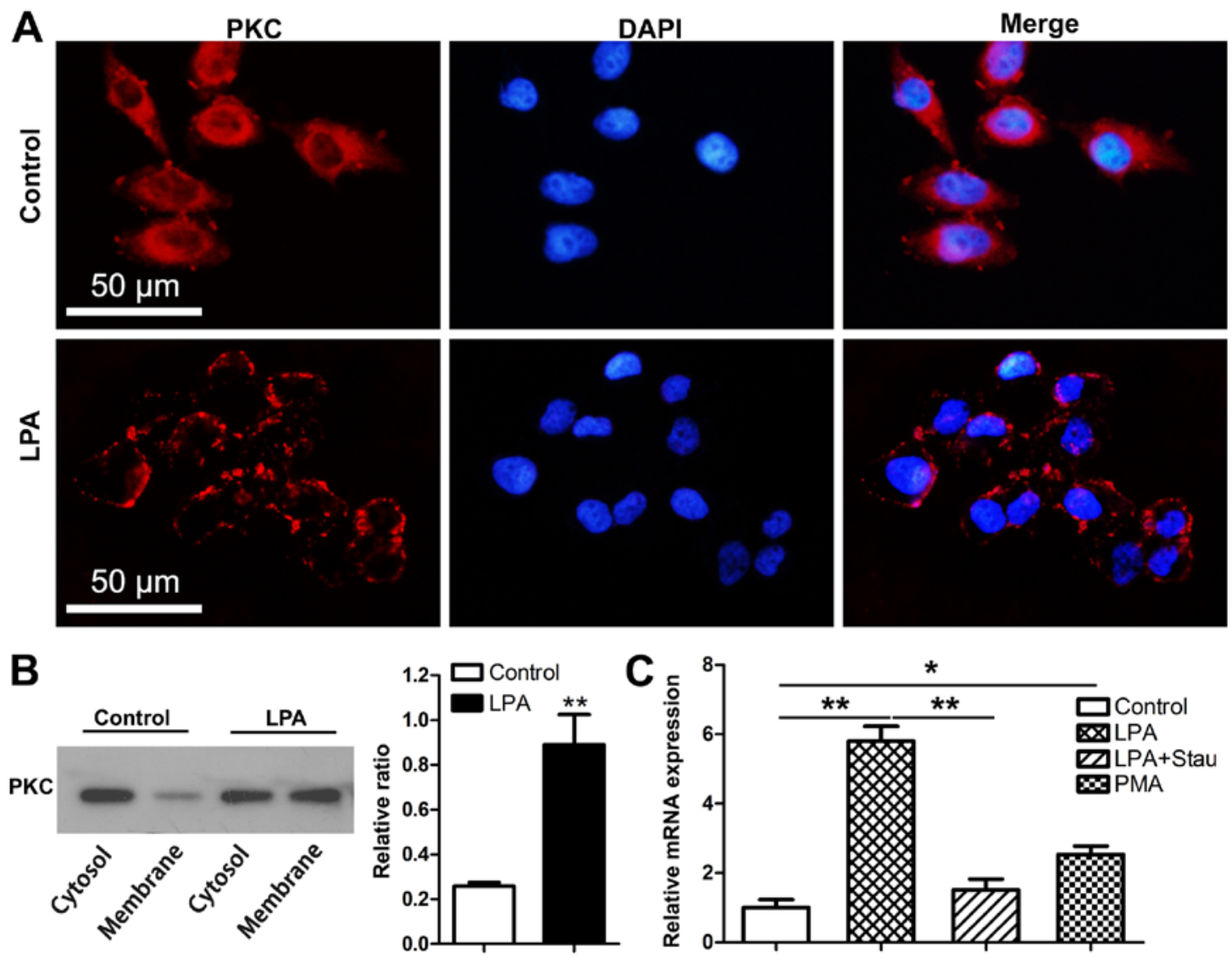

D
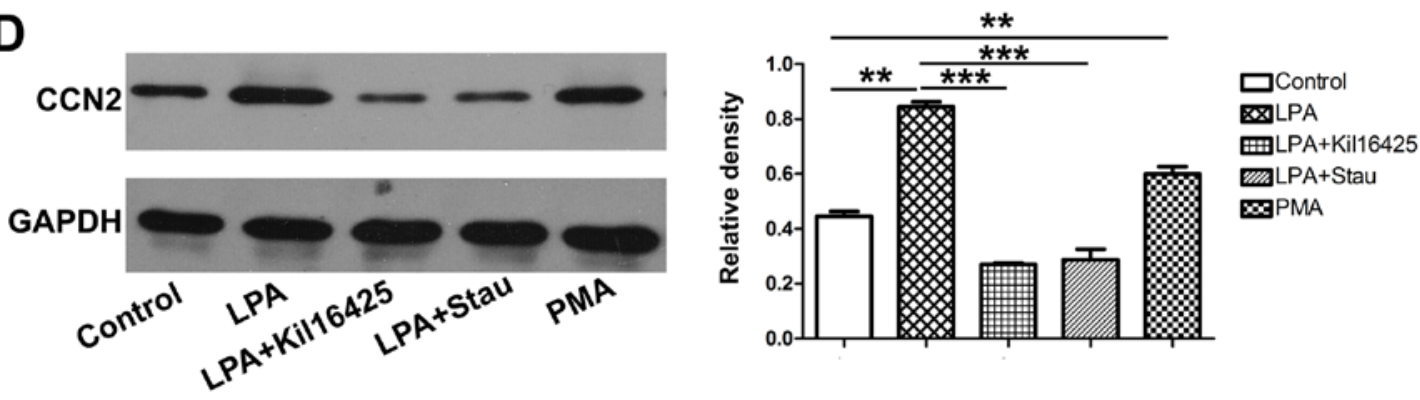

Figure 3. Induction of CCN2 expression in response to lysophosphatidic acid (LPA) requires the activation of protein kinase C (PKC). PKC translocation in MC3T3-E1 cells treated with $20 \mu \mathrm{M}$ LPA for $15 \mathrm{~min}$ was evaluated by (A) immunofluorescence staining and (B) western blot analysis. (C) CCN2 mRNA expression in MC3T3-E1 cells stimulated with LPA, with staurosporine (inhibitor of PKC)/LPA, and with phorbol 12-myristate 13-acetate (PMA; agonist of PKC) for $2 \mathrm{~h}$ was evaluated by RT-qPCR. (D) CCN2 protein expression in MC3T3-E1 cells stimulated with LPA, with Kil16425 (a specific inhibitor of LPA ${ }_{1 / 3}$ )/LPA, with staurosporine/LPA, and with PMA for $6 \mathrm{~h}$ was detected by western blot analysis. ${ }^{*} \mathrm{p}<0.05 ;{ }^{* *} \mathrm{p}<0.01$ and ${ }^{* * *} \mathrm{p}<0.001$.

LPA-induced increase in the protein expression of $\mathrm{CCN} 2$ in the MC3T3-E1 cells (Fig. 3D).

The effects of LPA on CCN2 expression may be attributed to $\mathrm{LPA}_{1}$ due to the very low expression of $\mathrm{LPA}_{3}$ (2). Thus, LPA induces an increase in CCN2 expression through the $\mathrm{LPA}_{1}$ receptor in MC3T3-E1 cells.

Effects of LPA on PKC activity. LPA receptors belong to the GPCR family (9). The LPA-induced activation of GPCR induces an increase in a variety of second messengers, such as $\mathrm{Ca}^{2+}$ in the cytoplasm of osteoblasts $(2,3,8,26) . \mathrm{Ca}^{2+}$ is essential for PKC membrane translocation and activation (27). The activation $\mathrm{PKC}$ is manifested by the membrane translocation of PKC (28) and PKC activity may be thus enhanced by LPA. In this study, the MC3T3-E1 cells were stimulated with LPA for $15 \mathrm{~min}$; PKC membrane translocation was observed by immunofluorescence staining (Fig. 3A). Western blot analysis revealed that LPA increased the ratio between membranederived PKC and cytosolic PKC (Fig. 3B). These results indicate that LPA induces PKC membrane translocation and enhances PKC activity in osteoblasts.

Induction of $C C N 2$ in response to $L P A$ requires the activation of PKC. Staurosporine and PMA, an inhibitor and an agonist of $\mathrm{PKC}$, respectively, were used to determine whether PKC is involved in the effects of LPA on CCN2 expression. Staurosporine $(20 \mathrm{nM})$ markedly impaired the ability of LPA to enhance CCN2 expression in the MC3T3-E1 cells, whereas PMA $(1 \mu \mathrm{M})$ mimicked LPA and induced the expression of CCN2 (Fig. 3C and D). 

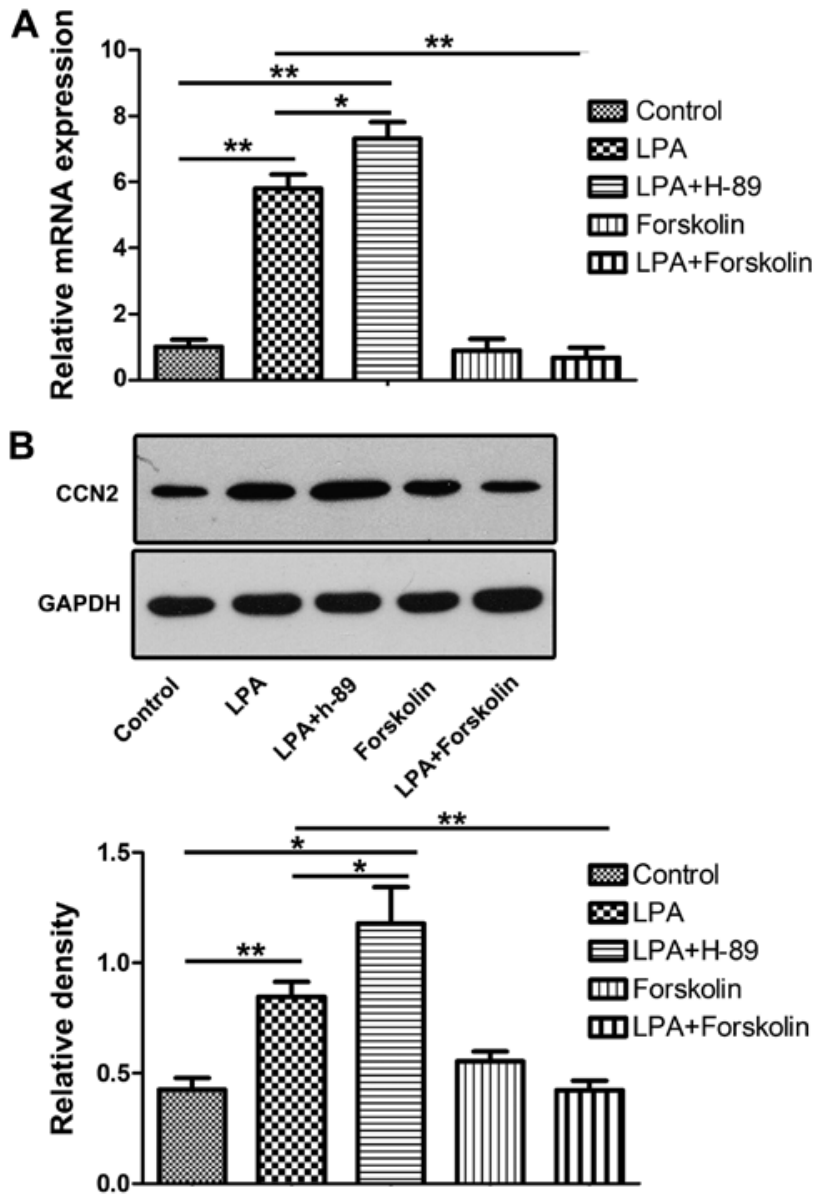

Figure 4. Effect of protein kinase A (PKA) on the lysophosphatidic acid (LPA)-induced increase in CCN2 expression. (A) CCN2 mRNA expression in MC3T3-E1 cells stimulated with LPA, with H-89 (a selective inhibitor of PKA)/LPA, with forskolin (PKA activator) and with forskolin/LPA for $2 \mathrm{~h}$ evaluated by RT-qPCR. (B) CCN2 protein expression following $6 \mathrm{~h}$ of treatment was evaluated by western blot analysis. ${ }^{*} \mathrm{P}<0.05$ and ${ }^{* *} \mathrm{P}<0.01$.
Effects of PKA on LPA-induced CCN2 expression. Cyclic AMP (cAMP), another second messenger, accumulates in cells expressing LPA $_{4,5}$ receptors $(29,30)$ in the presence of LPA; the accumulation of cAMP increases PKA activity. We thus examined the role of PKA in the expression of CCN2 in LPA-treated MC3T3-E1 cells. The MC3T3-E1 cells were pre-incubated with $\mathrm{H}-89(10 \mu \mathrm{M})$, a selective inhibitor of PKA, for $30 \mathrm{~min}$; LPA $(20 \mu \mathrm{M})$ was then added or the cells were treated with the PKA activator, forskolin, alone for 2 and $6 \mathrm{~h}$. The mRNA and protein expression levels of CCN2 in the LPA-H-89 group were enhanced compared with those of the LPA group (Fig. 4). Pre-treatment with forskolin $(10 \mu \mathrm{M})$ significantly decreased the mRNA and protein expression levels of of CCN2 which had been increased by LPA in the MC3T3-E1 cells. No significant effects were observed in the cells treated with forskolin alone compared to the cells also treated with LPA (Fig. 4).

\section{Discussion}

LPA is a small, bioactive phospholipid that mediates multiple cellular processes (1-6). Previous studies have demonstrated that LPA enhances CCN2 expression in epithelial cells, myoblasts and human renal fibroblasts $(13,19,20)$. However, the mechanisms through which LPA influences CCN2 expression in these cells remain unclear, and it is unknown whether LPA is capable of enhancing CCN2 expression in osteoblasts. In this study, we demonstrated that LPA induced CCN2 expression in MC3T3-E1 cells. To the best of our knowledge, our study provides preliminary data on LPA-induced CCN2 expression in MC3T3-E1 cells.

LPA receptors are GPCRs expressed in MC3T3-E1 cells (2). Given the dominant expression of $\mathrm{LPA}_{1}$, we used Kil16425, a specific inhibitor of $\mathrm{LPA}_{1 / 3}(25)$ to identify which LPA receptor subtype is involved in the LPA-induced increase

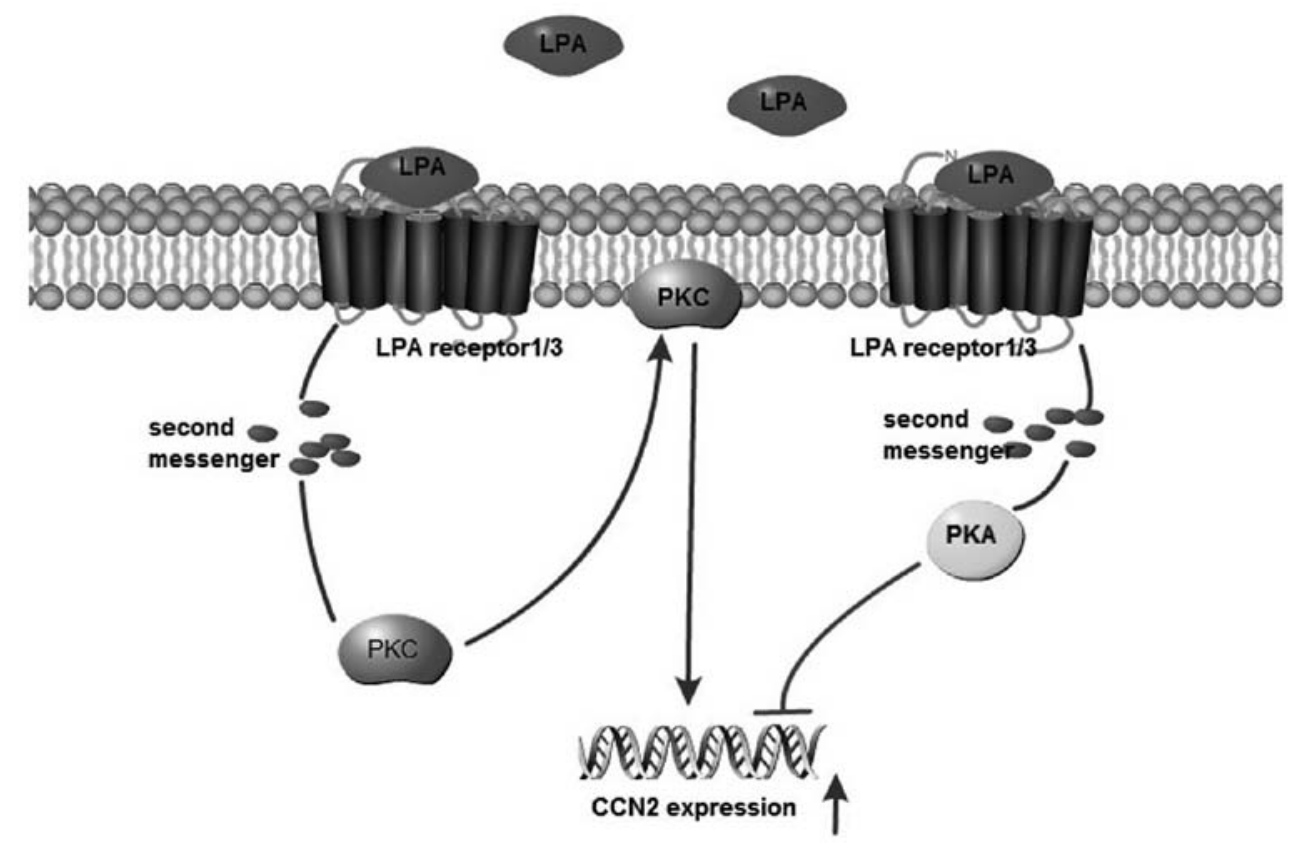

Figure 5. Schematic representation of the mechanisms responsible for the lysophosphatidic acid (LPA)-induced increase in connective tissue growth factor (CTGF/ $\mathrm{CCN} 2$ ) expression in osteoblasts. Binding of $\mathrm{LPA}$ and $\mathrm{LPA}_{1 / 3}$ led to protein kinase $\mathrm{C}(\mathrm{PKC})$ membrane translocation, which in turn promoted CCN2 expression. Simultaneously, the activation of $\mathrm{LPA}_{1 / 3}$ also inhibited $\mathrm{CCN} 2$ expression through the protein kinase A (PKA) pathway. 
in CCN2 expression. The results revealed that the LPA-induced increase in $\mathrm{CCN} 2$ expression in osteoblasts was antagonized by Kil16425.

The activation of LPA receptors by LPA increases the amount of various second messengers, such as $\mathrm{Ca}^{2+}$, which are required for PKC activation and membrane translocation in osteoblasts (31). Thus, in this study, we evaluated PKC activity in LPA-stimulated MC3T3-E1 cells. The membrane translocation of PKC in the MC3T3-E1 cells was induced by LPA following $15 \mathrm{~min}$ of stimulation. This finding indicated that LPA enhanced PKC activity in osteoblasts.

We subsequently examined the role of PKC in the LPA-induced increase in CCN2 expression. Pre-treatment with staurosporine significantly reduced the LPA-induced increase in CCN2 expression. Treatment with PMA alone enhanced the effects of LPA on CCN2 expression. Taken together, these findings demonstrate that the PKC pathway is involved in the LPA-induced increase in CCN2 expression, and thus a positive association between $\mathrm{CCN} 2$ expression and PKC activity was established herein. To the best of our knowledge, the present study is the first to demonstrate that the PKC pathway is involved in the promoting effects of LPA on CCN2 expression in MC3T3-E1 cells.

The cells pre-treated with the PKA inhibitor, H-89, and subsequently stimulated with LPA exhibited higher expression levels of CCN2 than the cells stimulated with LPA alone. The PKA activator, forskolin, had no effect on CCN2 expression compared to the cells stimulated with LPA alone. Our results are similar to those of other studies which concluded that cAMP stimulated CCN2 degradation in microvessel cells and decreased CCN2 expression in human renal fibroblasts; moreover, the results demonstrated that elevated intracellular cAMP levels activated PKA which in turn prevented the induction of CCN2 (20,32). Those results suggested that the PKA pathway reduced the LPA-induced increase in CCN2 expression in MC3T3-E1 cells.

The present study revealed the mechanisms responsible for the LPA-induced increase in CCN2 expression in MC3T3-E1 cells. We identified $\mathrm{LPA}_{1}$ as an important receptor in this process. Moreover, the PKC and PKA pathways were shown to be involved in the LPA-induced increase in CCN2 expression. The hypothetical signaling pathway of the LPA-induced increase in CCN2 expression in osteoblasts is illustrated in Fig. 5. These findings elucidated the mechanisms responsible for the increase in CCN2 expression in LPA-stimulated cells.

\section{Acknowledgements}

This study was supported by the National Natural Science Foundation of China (grant nos. 81271107 and 81470718).

\section{References}

1. Goetzl EJ: Pleiotypic mechanisms of cellular responses to biologically active lysophospholipids. Prostaglandins 64: 11-20, 2001

2. Masiello LM, Fotos JS, Galileo DS and Karin NJ: Lysophosphatidic acid induces chemotaxis in MC3T3-E1 osteoblastic cells. Bone 39: 72-82, 2006.

3. Liu YB, Kharode Y, Bodine PV, Yaworsky PJ, Robinson JA and Billiard J: LPA induces osteoblast differentiation through interplay of two receptors: $\mathrm{LPA}_{1}$ and $\mathrm{LPA}_{4}$. J Cell Biochem 109: 794-800, 2010.
4. Peyruchaud O, Leblanc R and David M: Pleiotropic activity of lysophosphatidic acid in bone metastasis. Biochim Biophys Acta 1831: 99-104, 2013.

5. Sims SM, Panupinthu N, Lapierre DM, Pereverzev A and Dixon SJ: Lysophosphatidic acid: a potential mediator of osteoblast-osteoclast signaling in bone. Biochim Biophys Acta 1831: 109-116, 2013.

6. Hurst-Kennedy J, Boyan BD and Schwartz Z: Lysophosphatidic acid signaling promotes proliferation, differentiation, and cell survival in rat growth plate chondrocytes. Biochim Biophys Acta 1793: 836-846, 2009.

7. Eichholtz T, Jalink K, Fahrenfort I and Moolenaar WH: The bioactive phospholipid lysophosphatidic acid is released from activated platelets. Biochem J 291: 677-680, 1993.

8. Panupinthu N, Rogers JT, Zhao L, Solano-Flores LP, Possmayer F, Sims SM and Dixon SJ: P2X7 receptors on osteoblasts couple to production of lysophosphatidic acid: a signaling axis promoting osteogenesis. J Cell Biol 181: 859-871, 2008.

9. Noguchi K, Herr D, Mutoh T and Chun J: Lysophosphatidic acid (LPA) and its receptors. Curr Opin Pharmacol 9: 15-23, 2009.

10. Fukushima N and Chun J: The LPA receptors. Prostaglandins Other Lipid Mediat 64: 21-32, 2001.

11. Dziak R, Yang BM, Leung BW, Li S, Marzec N, Margarone J and Bobek L: Effects of sphingosine-1-phosphate and lysophosphatidic acid on human osteoblastic cells. Prostaglandins Leukot Essent Fatty Acids 68: 239-249, 2003.

12. Vial C, Zúñiga LM, Cabello-Verrugio C, Cañón P, Fadic R and Brandan E: Skeletal muscle cells express the profibrotic cytokine connective tissue growth factor (CTGF/CCN2), which induces their dedifferentiation. J Cell Physiol 215: 410-421, 2008.

13. Wiedmaier N, Müller S, Köberle M, Manncke B, Krejci J, Autenrieth IB and Bohn E: Bacteria induce CTGF and CYR61 expression in epithelial cells in a lysophosphatidic acid receptordependent manner. Int J Med Microbiol 298: 231-243, 2008.

14. Brigstock DR: The CCN family: a new stimulus package. J Endocrinol 178: 169-175, 2003.

15. Brigstock DR, Goldschmeding R, Katsube KI, Lam SC, Lau LF, Lyons K, Naus C, Perbal B, Riser B, Takigawa M and Yeger H: Proposal for a unified CCN nomenclature. Mol Pathol 56: 127-128, 2003.

16. Kawaki H, Kubota S, Suzuki A, Yamada T, Matsumura T, Mandai T, Yao M, Maeda T, Lyons KM and Takigawa M: Functional requirement of $\mathrm{CCN} 2$ for intramembranous bone formation in embryonic mice. Biochem Biophys Res Commun 366: 450-456, 2008.

17. Nakanishi T, Nishida T, Shimo T, Kobayashi K, Kubo T, Tamatani T, Tezuka K and Takigawa M: Effects of CTGF/Hcs24, a product of a hypertrophic chondrocyte-specific gene, on the proliferation and differentiation of chondrocytes in culture. Endocrinology 141: 264-273, 2000.

18. Arnott JA, Lambi AG, Mundy C, Hendesi H, Pixley RA, Owen TA, Safadi FF and Popoff SN: The role of connective tissue growth factor $(\mathrm{CTGF} / \mathrm{CCN} 2)$ in skeletogenesis. Crit Rev Eukaryot Gene Expr 21: 43-69, 2011.

19. Cabello-Verrugio C, Córdova G, Vial C, Zúñiga LM and Brandan E: Connective tissue growth factor induction by lysophosphatidic acid requires transactivation of transforming growth factor type $\beta$ receptors and the JNK pathway. Cell Signal 23: 449-457, 2011.

20. Heusinger-Ribeiro J, Eberlein M, Wahab NA and Goppelt-Struebe M: Expression of connective tissue growth factor in human renal fibroblasts: regulatory roles of RhoA and cAMP. J Am Soc Nephrol 12: 1853-1861, 2001.

21. Chen G, Zhu JY, Zhang ZL, Zhang W, Ren JG, Wu M, Hong ZY, Lv C, Pang DW and Zhao YF: Transformation of cell-derived microparticles into quantum-dot-labeled nanovectors for antitumor siRNA delivery. Angew Chem Int Ed Engl 54: 1036-1040, 2015.

22. Li YG, Zhu W, Tao JP, Xin P, Liu MY, Li JB and Wei M: Resveratrol protects cardiomyocytes from oxidative stress through SIRT1 and mitochondrial biogenesis signaling pathways. Biochem Biophys Res Commun 438: 270-276, 2013.

23. Liu Q, Wan Q, Yang R, Zhou H and Li Z: Effects of intermittent versus continuous parathyroid hormone administration on condylar chondrocyte proliferation and differentiation. Biochem Biophys Res Commun 424: 182-188, 2012.

24. Grey A, Banovic T, Naot D, Hill B, Callon K, Reid I and Cornish J: Lysophosphatidic acid is an osteoblast mitogen whose proliferative actions involve $\mathrm{G}(\mathrm{i})$ proteins and protein kinase $\mathrm{C}$, but not P42/44 mitogen-activated protein kinases. Endocrinology 142: 1098-1106, 2001. 
25. Ohta H, Sato K, Murata N, Damirin A, Malchinkhuu E, Kon J, Kimura T, Tobo M, Yamazaki Y, Watanabe T, et al: Ki16425, a subtype-selective antagonist for EDG-family lysophosphatidic acid receptors. Mol Pharmacol 64: 994-1005, 2003.

26. Aki Y, Kondo A, Nakamura $\mathrm{H}$ and Togari A: Lysophosphatidic acid-stimulated interleukin-6 and -8 synthesis through LPA receptors on human osteoblasts. Arch Oral Biol 53: 207-213, 2008.

27. Escribá PV, Wedegaertner PB, Goñi FM and Vögler O: Lipid-protein interactions in GPCR-associated signaling. Biochim Biophys Acta 1768: 836-852, 2007.

28. Yuan X, Chen H, Li X, Dai M, Zeng H, Shan L, Sun Q and Zhang W: Inhibition of protein kinase $\mathrm{C}$ by isojacareubin suppresses hepatocellular carcinoma metastasis and induces apoptosis in vitro and in vivo. Sci Rep 5: 12889, 2015.
29. Lee CW, Rivera R, Gardell S, Dubin AE and Chun J: GPR92 as a new $\mathrm{G}_{12 / 13^{-}}$and $\mathrm{G}_{\mathrm{q}}$-coupled lysophosphatidic acid receptor that increases cAMP, LPA . J Biol Chem 281: 23589-23597, 2006.

30. Lee CW, Rivera R, Dubin AE and Chun J: LPA $(4) / G P R 23$ is a lysophosphatidic acid (LPA) receptor utilizing $\mathrm{G}_{(\mathrm{s})}{ }^{-}$, $\mathrm{G}_{(\mathrm{q})} / \mathrm{G}_{(\mathrm{i})}$-mediated calcium signaling and $\mathrm{G}_{(12 / 13)}$-mediated Rho activation. J Biol Chem 282: 4310-4317, 2007.

31. Lin ME, Herr DR and Chun J: Lysophosphatidic acid (LPA) receptors: signaling properties and disease relevance. Prostaglandins Other Lipid Mediat 91: 130-138, 2010.

32. Boes M, Dake BL, Booth BA, Erondu NE, Oh Y, Hwa V, Rosenfeld R and Bar RS: Connective tissue growth factor (IGFBP-rP2) expression and regulation in cultured bovine endothelial cells. Endocrinology 140: 1575-1580, 1999. 